CLINICAL STUDY

\title{
Genetic alterations in thyroid tumors from patients irradiated in childhood for tinea capitis treatment
}

\author{
Paula Boaventura $^{1}$, Dina Pereira ${ }^{1}$, Ricardo Celestino ${ }^{1}$, Adélia Mendes ${ }^{1}$, Tadao Nakasawa ${ }^{1,2}$, José Teixeira-Gomes ${ }^{1}$, \\ Manuel Sobrinho-Simões ${ }^{1,3,4}$ and Paula Soares ${ }^{1,3}$ \\ ${ }^{1}$ IPATIMUP - Institute of Molecular Pathology and Immunology of the University of Porto, Dr Roberto Frias s/n, 4200-465 Porto, Portugal, ${ }^{2}$ Department \\ of Pathology, Interdisciplinary Graduate School of Medicine and Engineering, University of Yamanashi, Yamanashi, Japan, ${ }^{3}$ Department of Pathology and \\ Oncology, Medical Faculty, University of Porto, Porto, Portugal and ${ }^{4}$ Department of Pathology, Hospital Centre of S. João, Porto, Portugal \\ (Correspondence should be addressed to P Boaventura; Email: mboaventura@ipatimup.pt)
}

\begin{abstract}
Objective: Exposure to ionizing radiation at young age is the strongest risk factor for the occurrence of papillary thyroid carcinoma (PTC). RET/PTC rearrangements are the most frequent genetic alterations associated with radiation-induced PTC, whereas BRAF and RAS mutations and PAX8-PPARG rearrangement have been associated with sporadic PTC. We decided to search for such genetic alterations in PTCs of patients subjected in childhood to scalp irradiation.

Design: We studied 67 thyroid tumors from 49 individuals irradiated in childhood for tinea capitis scalp epilation: 36 malignant (12 cases of conventional PTC (cPTC), two cPTC metastases, 20 cases of follicular variant PTC (FVPTC), one oncocytic variant of PTC and one follicular carcinoma) and 31 follicular thyroid adenomas.

Methods: The lesions were screened for the BRAF $F^{V 600 E}$ and NRAS mutations and for RET/PTC and PAX8-PPARG rearrangements.

Results: BRAF ${ }^{V 600 E}$ mutation was detected in seven of $14(50 \%)$ cPTC and two of 20 FVPTC (10\%) $(P=0.019)$. NRAS mutation was present in one case of FVPTC $(5 \%)$. RET/PTC1 rearrangement was found, by RT-PCR, in one of 17 cases ( $5.9 \%$ ) and by fluorescence in situ hybridization in two of six cases (33\%). PAX8-PPARG rearrangement was not detected in any carcinoma. None of the follicular adenomas presented any of the aforementioned genetic alterations.

Conclusions: The prevalence of $B R A F^{V 600 E}$ mutation in our series is the highest reported in series of PTCs arising in radiation-exposed individuals. The prevalence of RET/PTC1 rearrangement fits with the values recently described in a similar setting.
\end{abstract}

European Journal of Endocrinology 169 673-679

\section{Introduction}

Exposure to ionizing radiation at young age is known as the strongest risk factor for thyroid carcinoma development, namely papillary thyroid carcinoma (PTC) (1), which is the most frequent histotype representing $80 \%$ of all thyroid tumors. Thyroid is very sensitive to both external and internal radiation, being the only organ with a documented major rise in cancer incidence after radiation exposure, especially in childhood (2). However, the data on the effects of low-dose radiation remain limited (3).

X-ray scalp epilation for tinea capitis treatment, applying a mean average dose to the thyroid gland of 9.3 cGy (range 4.5-49.5 cGy), has shown to increase thyroid cancer risk (4). It is not yet known whether scalp radiation-associated thyroid cancers have the same genetic alterations and clinical behaviour as the sporadic thyroid cancers (5).
Four mutation types constitute the majority of known mutations in thyroid cancer and carry the highest impact on tumor diagnosis and prognosis: $B R A F$ and RAS point mutations and RET/PTC and PAX8-PPARG rearrangements (6). It was advanced that the dominant mutation mechanism in radiation-induced tumors is chromosomal rearrangement, whereas point mutation is the most prevalent mechanism in sporadic tumors (1). In radiation-induced tumors, namely in postChernobyl PTCs, RET/PTC rearrangements can be detected in up to $84 \%$ of PTCs $(1,7,8)$ and up to $52 \%$ of thyroid adenomas $(7,8,9,10)$, but some studies showed lower values, $34-51 \%(11,12)$, and $43 \%$ in a population exposed to external radiation (10). In sporadic, non-irradiated thyroid tumors, RET/PTC rearrangement frequency can be as low as $5-15 \%(7)$. PAX8-PPARG fusion oncogene has been identified as more prevalent in follicular carcinoma (13), but was also found in 1-38\% of cases of follicular variant of PTC 
(FVPTC) $(14,15,16)$, and in $2-33 \%$ of cases of follicular adenoma $(15,16)$.

At variance with radiation-induced tumors, the most prevalent mechanism in sporadic tumors is point mutation, typically involving the $B R A F$ and $R A S$ genes (1). BRAF mutations occur in $\sim 45-53 \%$ of adult sporadic PTCs $(17,18)$, being considered as rare events in subjects exposed to radiation in children, both internal and external, with frequencies ranging from 4 to $24 \%(12,19,20)$. Recently, however, Dinets et al. (11) reported a BRAF mutation prevalence of $37 \%$ in a recent study of post-Chernobyl cases. These authors also detected the co-occurrence of RET/PTC and BRAF mutation (11). In atomic bomb survivors, Hamatani et al. (21) found that RET/PTC rearrangement, and not BRAF mutations, were closely associated with radiation-associated adult-onset PTC.

RAS mutations have been detected in 10-20\% of PTCs, virtually all belonging to the follicular variant (22) and in $20-40 \%$ of follicular adenomas (15). RAS can present three isoforms being the NRAS isoform predominantly mutated in thyroid tumors (23). No major difference has been associated with the radiation in comparison with the sporadic setting (24). Recently, Leeman-Neill et al. (25) reported an $8 \%$ prevalence of RAS mutations in a post-Chernobyl cohort.

The aim of this study was to evaluate the aforementioned genetic alterations in PTCs following X-ray external radiation performed in childhood to induce scalp epilation for tinea capitis treatment, a cohort in which we have already shown a high prevalence of thyroid cancer (26). As far as we know, only RET/PTC rearrangements have been studied in similar cohorts (10).

\section{Subjects and methods}

\section{Cases}

We have clinically observed 1287 individuals from an original cohort of 5356 individuals who had been submitted in childhood to scalp irradiation for tinea capitis treatment (26). Briefly, the standard treatment was done according to the Kienbock-Adamson technique (27) using one X-ray epilation session (325400R); $6 \%$ of the 5356 individuals $(n=318)$ were submitted to two or three sessions (irradiation dose $\geq 630 \mathrm{R}$ ) (26).

Thirty-five patients with thyroid cancer and 38 patients with follicular adenoma were identified. Sixtyseven thyroid tumors from 49 participants were retrieved from several pathology departments and laboratories and were histologically re-evaluated by two pathologists (M S-S and T N). Formalin-fixed and paraffin-embedded (FFPE) blocks from 24 of the 35 patients with thyroid carcinoma (69\%) and from 28 of the 38 patients with follicular adenoma (74\%) were examined. Some patients presented more than one lesion $(n=9)$, leading to a total of 36 thyroid carcinomas and 31 follicular adenomas.

All the procedures were performed under strict ethical and confidentiality procedures according to the Portuguese ethical rules. The study was approved by the Ethics Committee of the Hospital Pedro Hispano and all the patients signed an informed consent.

\section{Identification of BRAF and NRAS mutations}

Genomic DNA was extracted from microdissected FFPE pathological tissue, using $10 \mu \mathrm{m}$ sections, by conventional overnight incubation with proteinase K. Subsequent DNA purification was performed using Invisorb Spin Tissue Mini Kit (Invitek, Berlin, Germany) according to the manufacturer's protocol.

The following specific PCR primers were used to flank the mutational hotspot region of $B R A F$ activation segment (exon 15) and NRAS exon 2: forward primer for BRAF, 5'-TCATAATGCTTGCTCTGATAGGA-3' and the reverse primer, 5'-GGCCAAAAATTTAATCAGTGGA3'; for the NRAS exon 2 amplification, the forward primer used was $5^{\prime}$-GATTCTTACAGAAAACAAGT- $3^{\prime}$ and the reverse was 5'-GAAAATAATGCTCCTAGTAC-3'. All the procedures, including automated sequencing, were performed as described previously (16).

Briefly, PCR amplifications were performed in a $25 \mu \mathrm{l}$ volume reaction containing 25-100 ng genomic DNA, $200 \mu \mathrm{M}$ each dNTP, $0.1 \mu \mathrm{g}$ of each, forward and reverse, primer, $1 \times$ GoTaq Flexi Buffer (Promega), $2.5 \mathrm{mM} \mathrm{MgCl}_{2}$ and $0.75 \mathrm{U}$ of Taq DNA polymerase (Promega). Reaction mixtures were submitted to 40 amplification cycles preceded by a Taq activation step at $95^{\circ} \mathrm{C}$ for $5 \mathrm{~min}$, each cycle comprised a denaturation step at $95^{\circ} \mathrm{C}$ for $30 \mathrm{~s}$, annealing at $58^{\circ} \mathrm{C}$ for $40 \mathrm{~s}$ and extension at $72{ }^{\circ} \mathrm{C}$ for $45 \mathrm{~s}$ followed by a final extension at $72{ }^{\circ} \mathrm{C}$ for $10 \mathrm{~min}$. PCR products were then purified using enzymatic digestion with Exonuclease I (Fermentas, Vilnius, Lithuania) and Shrimp Alkaline Phosphatase (Fermentas) and sequenced using an ABI Prism BigDye Terminator Cycle Sequencing Kit (Perkin-Elmer, Foster City, CA, USA) and an ABI Prism 377 DNA Sequencer (Perkin-Elmer). All the detected mutations were further validated by a new independent amplification and sequencing.

\section{Identification of RET/PTC and PAX8-PPARG rearrangements}

Total RNA was extracted from paraffin-embedded tissues using the RecoverAll Nucleic Acid Isolation Kit for FFPE (Ambion - Life Technologies, Foster City, CA, USA) according to the manufacturer's instructions.

The cDNA was obtained using the RevertAid Reverse Transcriptase (Thermo Scientific, Waltham, MA, USA) at $37{ }^{\circ} \mathrm{C}$ for $60 \mathrm{~min}$, followed by enzyme inactivation at $99^{\circ} \mathrm{C}$ for $5 \mathrm{~min}$. The PCR using cDNA was performed with HotStart Taq DNA polymerase kit (Qiagen Co.) and initiated by denaturation at $95^{\circ} \mathrm{C}$ for $15 \mathrm{~min}$ followed 

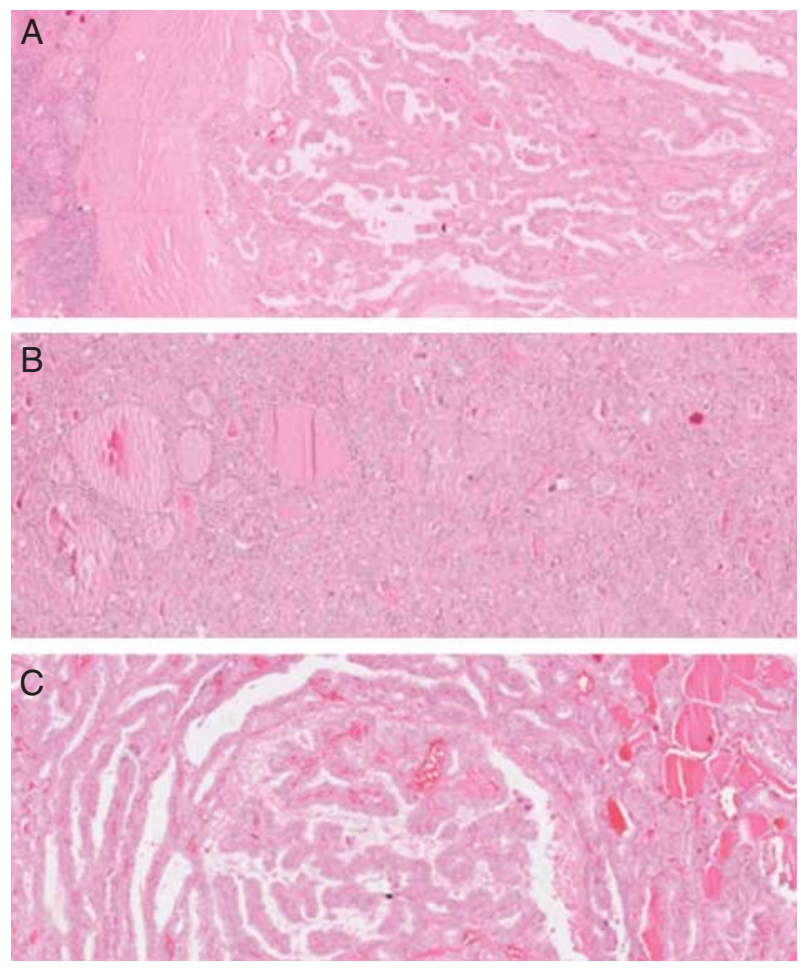

Figure 1 Photomicrographs of haematoxylin-stained slides showing histopathological findings. (A) CPTC presenting RET/PTC1 rearrangement detected by RT-PCR and FISH; (B) FVPTC presenting RET/PTC1 rearrangement detected only by FISH; (C) CPTC presenting BRAF ${ }^{\mathrm{V} 600 \mathrm{E}}$ mutation $(100 \times)$.

by 30 cycles of $30 \mathrm{~s}$ at $95^{\circ} \mathrm{C}, 75 \mathrm{~s}$ at $56-60{ }^{\circ} \mathrm{C}$ and $30 \mathrm{~s}$ at $72{ }^{\circ} \mathrm{C}$, before a final elongation step at $72{ }^{\circ} \mathrm{C}$ for $6 \mathrm{~min}$. The RT-PCR products were analyzed by $2 \%$ agarose gel electrophoresis. PCRs creating a visible band on the gel were sequenced directly (ABI 3730 DNA analyser; Applied Biosystems by Life Technologies). The housekeeping GAPDH gene was also amplified to control the cDNA integrity of the samples. Primers for cDNA amplification: RET-PTC1 rearrangement: 5'-GTCGGGGGGCATTGTCATCT (CCDC6, exon 1), 3'-AAGTTCTTCCGAGGGAATTC (RET, exon 12). RETPTC3 rearrangement: 5'-TGGAGAAGAGAGGCTGTATC (NCOA4, exon 6); 3'-CTTTCAGCATCTTCACGG (RET, exon 12). PAX8-PPARG rearrangements: PAX8-PPARG (F7): 5'-AACCTCTCGACTCACCAGAC (PAX8, exon 7), 3'-TGGGAGTGGTCTTCCATTACG (PPARG, exon 1); PAX8-PPARG (F8): 5'-CCCTTCAATGCCTTTCCCC, 3'-TGGGAGTGGTCTTCCATTACG (PPARG, exon 1); PAX8PPARG (F9): 5'-CTATGCCTCCTCTGCCATC (PAX8, exOn 9), 3'-TGGGAGTGGTCTTCCATTACG (PPARG, exon 1).

In addition to RT-PCR approach, fluorescence in situ hybridization (FISH) was performed in tumor samples in order to confirm the RET/PTC rearrangements. Briefly, isolated nuclei were extracted from $50 \mu \mathrm{m}$ sections of FFPE thyroid tumor tissues. The isolation of nuclei from FFPE tissue and FISH technique was performed following the procedure described by Marques et al. (28). RET/PTC rearrangement detection was investigated with a DNA probe generated from three yeast artificial chromosome clones $(313 \mathrm{~F} 4,214 \mathrm{H} 10$, and 344H4) covering the RET locus (kindly provided by Prof. Horst Zitzelsberger); probe hybridization was performed as described (29). FISH signals were analyzed and recorded with a CytoVision System (Applied Imaging, New Castle, UK). For RET/PTC, at least 200 nuclei were scored for the presence of a split FISH signal (rearranged) in addition to an overlapping signal (normal). Only cells with either two overlapping signals or one split and one overlapping signal were counted to ensure that only intact nuclei had been scored. Only when $10 \%$ or more rearranged nuclei were present, we considered the case as positive for RET/PTC or PAX8-PPARG rearrangements (30).

Samples of thyroid cancer, positive for RET/PTC1 or RET/PTC3 rearrangements by RT-PCR and cDNA sequencing, were used as positive controls for FISH.

\section{Results}

\section{Histopathology}

All the lesions were observed and reclassified independently by two pathologists (M S-S and T N), being 36 malignant and 31 follicular adenomas. The malignant lesions included 12 conventional PTC (cPTC), 20 FVPTC, one oncocytic variant of PTC, two lymph nodes metastases of cPTC and one follicular carcinoma.

\section{BRAF and NRAS mutations}

The BRAF ${ }^{V 600 E}$ mutation was detected in nine of 36 malignant lesions $(25 \%)$, two cases of FVPTC $(10 \%)$ (Fig. 1A) and seven of cPTC (50\%) (Fig. 1B), this difference being significant (Table 1) $(P=0.019)$. In one case of cPTC, there was insufficient material from the tumor for further analysis.

There were no differences in the $B R A F^{V 600 E}$ mutation prevalence according to gender, age at irradiation, age at diagnosis, latency period (time between irradiation and surgery) nor any clinicopathological parameter, either considering tumors or individual patients. Only

Table 1 Frequency of $B R A F^{V 600 E}$ and RAS mutations in 67 thyroid tumors from childhood scalp-irradiated individuals.

\begin{tabular}{lll}
\hline $\begin{array}{l}\text { Histological type } \\
\text { or subtype }\end{array}$ & $\begin{array}{l}\text { BRAFV600E } \\
\text { positive }\end{array}$ & $\begin{array}{l}\text { RAS } \\
\text { positive }\end{array}$ \\
\hline $\begin{array}{l}\text { Conventional PTC (12 primary } \\
\text { tumor + two metastasized lymph }\end{array}$ & $7 / 14(50 \%)$ & None \\
$\quad$ node) $(n=14)$ & & \\
$\begin{array}{l}\text { Follicular variant of PTC }(n=20) \\
\text { Oncocytic variant of PTC }(n=1)\end{array}$ & $2 / 20(10 \%)$ & $1 / 20(5 \%)$ \\
$\begin{array}{l}\text { Follicular carcinoma }(n=1) \\
\text { Follicular adenoma }(n=31)\end{array}$ & None & $\begin{array}{l}\text { None } \\
\text { None }\end{array}$ \\
\hline
\end{tabular}




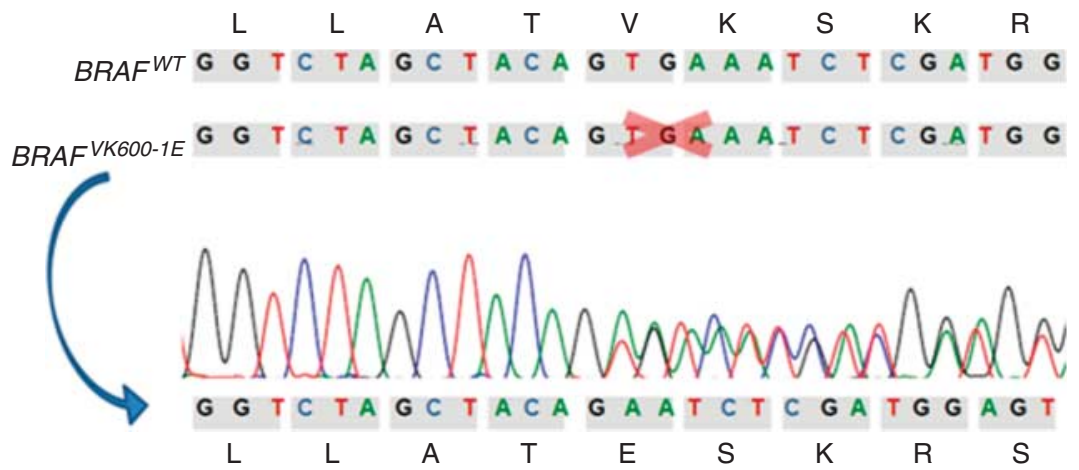

Figure 2 Sequencing profile/electropherogram of the sample with the $B R A F^{V K 60 O E-1 E}$ mutation. Full colour version of this figure available via http://dx.doi.org/10.1530/ EJE-13-0543.

two thyroid cancer patients had been submitted to a higher irradiation dose, so it was not possible to evaluate the dose effect in the $B R A F^{V 600 E}$ mutation prevalence. One of the 20 cases of FVPTC showed the rare $B R A F^{V K 60 O E-1 E}$ mutation, described by our group (31) (Fig. 2). None of the benign lesions - follicular adenomas - presented BRAF mutation. NRAS mutation was detected in only one case of FVPTC.

\section{RET/PTC and PAX8-PPARG rearrangements}

RNA was successfully recovered in 32 thyroid tumors (15 benign and 17 malignant). By RT-PCR, RET/PTC1 rearrangement was detected in only one of 17 cases of thyroid cancer (5.9\%), a case of cPTC (Figs $1 \mathrm{C}$ and 3 ). The RET/PTC1 rearrangement was not identified in any of the follicular adenomas $(n=15)$.

All the carcinomas for which there was enough material for FISH study $(n=6)$ were evaluated by this assay. In two of six cases (33.3\%), the RET/PTC1 rearrangement was detected, confirming the case already observed by RT-PCR (Fig. 4). The other case detected by FISH was a case of a FVPTC. No PAX8PPARG rearrangements were detected in any case. All the mutations/rearrangements were mutually exclusive.

\section{Discussion}

Almost all the carcinomas found in this series of childhood-irradiated individuals were PTCs (35/36, $97.2 \%$ ). Radiation exposure has been described as significantly increasing the risk for thyroid malignancies, particularly PTC (32), in accordance with the results of the present series. We observed the FVPTC in
$55.6 \%$ of the PTCs $(20 / 36)$. In other series of PTCs, the prevalence of the FVPTC varied from 7 to $53 \%(33,34$, $35,36,37,38)$, our frequency being similar to the higher value of this range, but no reports were found referring in particular the prevalence of FVPTC in the irradiation context. The high variation in the frequency of FVPTC observed can be due to different evaluation criteria adopted in the diverse studies published to date.

Our results show that the prevalence of $B R A F^{V 600 E}$ mutation in our series is in the high range of that reported in PTCs of radiation-exposed individuals (internal or external) $(4-24 \%)$ and lower than the values referred for sporadic PTCs (45-53\%) (39). We found that the $B R A F^{V 600 E}$ mutation was significantly more prevalent in the cPTC $(50 \%)$ than in FVPTC $(10 \%)$, in accordance with the $35-70$ vs $5-20 \%$ reported by us and others for sporadic PTC $(39,40)$. We did not find any significant difference regarding the prevalence of histological subtypes or presence of $B R A F$ mutation according to age, gender, latency and clinicopathological parameters.

RET/PTC1 rearrangement was detected in $6 \%$ of the thyroid carcinomas using RT-PCR $(n=17)$, but this value increased to $33 \%$ in the six cases in which it was possible to use FISH. FISH has been considered as the assay of choice for rearrangement detection, although its use in FFPE tissue is hampered by the quality of the material and size of the lesions. In fact, the technique is not feasible in small PTCs that represented part of the cases of our series. A prevalence of 33\% may still be assumed as a low figure for this rearrangement in the context of thyroid irradiation, although the values reported in the literature have been decreasing recently. Dinets et al. (11) found a 29\% prevalence for RET/PTC1 rearrangement and a $6 \%$ prevalence for RET/PTC 3 rearrangement in a recent study of adult post-Chernobyl

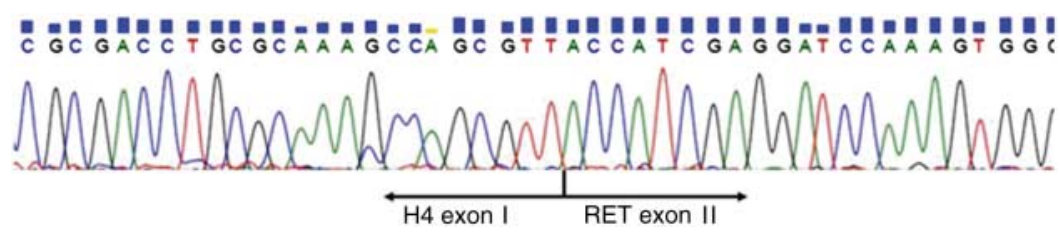

Figure 3 Sequencing profile/electropherogram of one sample with the RET/PTC1 rearrangement. Full colour version of this figure available via http://dx.doi.org/10.1530/EJE-13-0543. 


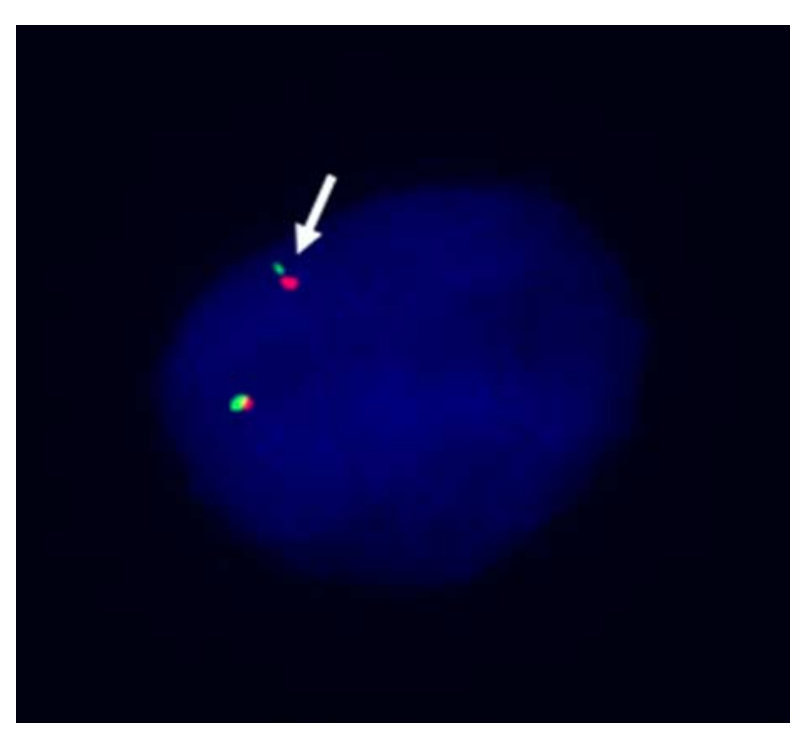

Figure 4 RET/PTC1 rearrangement (arrow) (this case was also positive by RT-PCR). Magnification: $\times 1000$. Full colour version of this figure available via http://dx.doi.org/10.1530/EJE-13-0543.

PTC cases. The variation in the prevalence and specificity of RET/PTC rearrangements reported in different series can be due to differences in the prevalence of this alteration in specific age groups (15).

Nevertheless, Elisei et al. (9) reported that the presence of RET/PTC rearrangements was not higher in radiation-induced tumors compared with those naturally occurring, nor different after exposure to radioiodine or external radiation; it was also not dependent on age at irradiation. At variance with Elisei et al., other authors advanced that the prevalence of the different genetic alterations can vary with the time of latency of the tumors. In Chernobyl context, it was verified that the prevalence of RET/PTC in short latency period tumors ('first wave') was higher than in tumors that arise later ('second wave') (41). The tumors we have analysed in the present series have a long latency period ( $\geq 30$ years).

By RT-PCR, the PAX8-PPARG rearrangement was not observed in any of the FVPTC of the present series. In a previous study, we have detected, by FISH, PAX8PPARG rearrangement in $37.5 \%$ of sporadic cases of FVPTC (16). In another study of sporadic FVPTC, this rearrangement was undetectable by RT-PCR in all the seven cases studied (42). One limitation of this study was the fact that we had insufficient tumor material, due to small tumor size, to apply the FISH technique to most of our cases. The rearrangement was not detected in any follicular adenoma, in accordance with Dwight et al. (43) and differently from the 33\% prevalence in sporadic follicular adenomas (16).

In conclusion, we report a thorough histological and genetic characterization of thyroid tumors arising, after a long latency period, in the context of low-dose external irradiation (scalp). We also report for the first time data on the prevalence of FVPTC in tinea capitis irradiation context, the results of the present series being slightly above the highest values reported in sporadic PTCs. Moreover, with the exception of RET/PTC rearrangements, the other common genetic alterations in thyroid cancer (BRAF and NRAS mutations and PAX8-PPARG rearrangements) had never been studied in this low-dose external radiation context. Further studies are needed, with larger series, in order to clarify, using FISH technique, the actual importance of these rearrangements when the thyroid is submitted to lowdose external radiation. This is important if we take into account that radiotherapy for head and neck cancers, thorax cancers, lymphomas, breast cancers and even all body irradiation may expose the thyroid to radiation due to its anatomical position (44).

\section{Declaration of interest}

The authors declare that there is no conflict of interest that could be perceived as prejudicing the impartiality of the research reported.

\section{Funding}

This work was supported by grants from Calouste Gulbenkian Foundation (ref. 76636) and Portuguese Foundation for Science and Technology (FCT) (project: PIC/IC/83154/2007) and by project 'Microenvironment, metabolism and cancer' partially supported by Programa Operacional Regional do Norte (ON.2 - O Novo Norte) under the Quadro de Referência Estratégico Nacional (QREN) and through the Fundo Europeu de Desenvolvimento Regional (FEDER) and additional funding from FCT grant to $\mathrm{P}$ Boaventura (SFRH/BPD/34276/2007). IPATIMUP is an Associate Laboratory of the Portuguese Ministry of Science, Technology and Higher Education and is partially supported by FCT.

\section{Acknowledgements}

Gratefulness is also due to all the patients that agreed to participate in this study as well as to all the physicians that provided clinical information. Prize ACS-MERCK SERONO in Cancer Epidemiology, 2010 .

\section{References}

1 Nikiforov YE. Is ionizing radiation responsible for the increasing incidence of thyroid cancer? Cancer 2010116 1626-1628. (doi:10.1002/cncr.24889)

2 Wartofsky L. Increasing world incidence of thyroid cancer: increased detection or higher radiation exposure? Hormones 20109 103-108.

3 Abou-El-Ardat K, Monsieurs P, Anastasov N, Atkinson M, Derradji H, De Meyer $\mathrm{T}$, Bekaert $\mathrm{S}$, Van Criekinge $\mathrm{W}$ \& Baatout S. Low dose irradiation of thyroid cells reveals a unique transcriptomic and epigenetic signature in RET/PTC-positive cells. Mutation Research 2012731 27-40. (doi:10.1016/j.mrfmmm. 2011.10.006)

4 Sadetzki S, Chetrit A, Lubina A, Stovall M \& Novikov I. Risk of thyroid cancer after childhood exposure to ionizing radiation for tinea capitis. Journal of Clinical Endocrinology and Metabolism 2006 91 4798-4804. (doi:10.1210/jc.2006-0743) 
5 Sinnott B, Ron E \& Schneider AB. Exposing the thyroid to radiation: a review of its current extent, risks, and implications. Endocrine Reviews 201031 756-773. (doi:10.1210/er.20100003)

6 Nikiforova MN \& Nikiforov YE. Molecular diagnostics and predictors in thyroid cancer. Thyroid 200919 1351-1361. (doi:10.1089/thy.2009.0240)

7 Rubino C, Cailleux AF, De Vathaire F \& Schlumberger M. Thyroid cancer after radiation exposure. European Journal of Cancer 2002 38 645-647. (doi:10.1016/S0959-8049(02)00009-6)

8 Bounacer A, Wicker R, Caillou B, Cailleux AF, Sarasin A, Schlumberger M \& Suarez HG. High prevalence of activating ret proto-oncogene rearrangements, in thyroid tumors from patients who had received external radiation. Oncogene $1997 \mathbf{1 5}$ 1263-1273. (doi:10.1038/sj.onc.1200206)

9 Elisei R, Romei C, Vorontsova T, Cosci B, Veremeychik V, Kuchinskaya E, Basolo F, Demidchik EP, Miccoli P, Pinchera A et al. RET/PTC rearrangements in thyroid nodules: studies in irradiated and not irradiated, malignant and benign thyroid lesions in children and adults. Journal of Clinical Endocrinology and Metabolism 200186 3211-3216. (doi:10.1210/jc.86.7.3211)

10 Sadetzki S, Calderon-Margalit R, Modan B, Srivastava S \& Tuttle RM. Ret/PTC activation in benign and malignant thyroid tumors arising in a population exposed to low-dose external-beam irradiation in childhood. Journal of Clinical Endocrinology and Metabolism 200489 2281-2289. (doi:10.1210/jc.2003030481)

11 Dinets A, Hulchiy M, Sofiadis A, Ghaderi M, Hoog A, Larsson C \& Zedenius J. Clinical, genetic, and immunohistochemical characterization of 70 Ukrainian adult cases with post-Chornobyl papillary thyroid carcinoma. European Journal of Endocrinology $201216 \mathbf{6 6}$ 1049-1060. (doi:10.1530/EJE-12-0144)

12 Tronko M, Bogdanova T, Voskoboynyk L, Zurnadzhy L, Shpak V \& Gulak L. Radiation induced thyroid cancer: fundamental and applied aspects. Experimental Oncology 201032 200-204.

13 Eberhardt NL, Grebe SK, McIver B \& Reddi HV. The role of the PAX8/PPARgamma fusion oncogene in the pathogenesis of follicular thyroid cancer. Molecular and Cellular Endocrinology 2010321 50-56. (doi:10.1016/j.mce.2009.10.013)

14 Placzkowski KA, Reddi HV, Grebe SK, Eberhardt NL \& McIver B. The role of the PAX8/PPARgamma fusion oncogene in thyroid cancer. PPAR Research $2008 \mathbf{2 0 0 8} 672829$. (doi:10.1155/2008/ 672829)

15 Nikiforov YE \& Nikiforova MN. Molecular genetics and diagnosis of thyroid cancer. Nature Reviews. Endocrinology 2011 7 569-580. (doi:10.1038/nrendo.2011.142)

16 Castro P, Rebocho AP, Soares RJ, Magalhaes J, Roque L, Trovisco V, Vieira de Castro I, Cardoso-de-Oliveira M, Fonseca E, Soares P et al. PAX8-PPARgamma rearrangement is frequently detected in the follicular variant of papillary thyroid carcinoma. Journal of Clinical Endocrinology and Metabolism 200691 213-220. (doi:10.1210/ jc.2005-1336)

17 Ciampi R \& Nikiforov YE. RET/PTC rearrangements and BRAF mutations in thyroid tumorigenesis. Endocrinology $2007 \mathbf{1 4 8}$ 936-941. (doi:10.1210/en.2006-0921)

18 Fukushima T, Suzuki S, Mashiko M, Ohtake T, Endo Y, Takebayashi Y, Sekikawa K, Hagiwara K \& Takenoshita S. BRAF mutations in papillary carcinomas of the thyroid. Oncogene 2003 22 6455-6457. (doi:10.1038/sj.onc.1206739)

19 Collins BJ, Schneider AB, Prinz RA \& Xu X. Low frequency of BRAF mutations in adult patients with papillary thyroid cancers following childhood radiation exposure. Thyroid 200616 61-66. (doi:10.1089/thy.2006.16.61)

20 Lima J, Trovisco V, Soares P, Maximo V, Magalhaes J, Salvatore G, Santoro M, Bogdanova T, Tronko M, Abrosimov A et al. BRAF mutations are not a major event in post-Chernobyl childhood thyroid carcinomas. Journal of Clinical Endocrinology and Metabolism 200489 4267-4271. (doi:10.1210/jc.2003-032224)

21 Hamatani K, Eguchi H, Ito R, Mukai M, Takahashi K, Taga M, Imai K, Cologne J, Soda M, Arihiro K et al. RET/PTC rearrangements preferentially occurred in papillary thyroid cancer among atomic bomb survivors exposed to high radiation dose. Cancer Research 200868 7176-7182. (doi:10.1158/0008-5472.CAN08-0293)

22 Bhaijee F \& Nikiforov YE. Molecular analysis of thyroid tumors. Endocrine Pathology 201122 126-133. (doi:10.1007/s12022011-9170-y)

23 Xing M. Molecular pathogenesis and mechanisms of thyroid cancer. Nature Reviews. Cancer 201313 184-199. (doi:10.1038/ $\operatorname{nrc3431)}$

24 Suarez HG. Genetic alterations in human epithelial thyroid tumours. Clinical Endocrinology $1998 \mathbf{4 8}$ 531-546. (doi:10. 1046/j.1365-2265.1998.00443.x)

25 Leeman-Neill RJ, Brenner AV, Little MP, Bogdanova TI, Hatch M, Zurnadzy LY, Mabuchi K, Tronko MD \& Nikiforov YE. RET/PTC and PAX8/PPARgamma chromosomal rearrangements in postChernobyl thyroid cancer and their association with iodine-131 radiation dose and other characteristics. Cancer 2013119 1792-1799. (doi:10.1002/cncr.27893)

26 Boaventura P, Soares P, Pereira D, Teixeira-Gomes J \& SobrinhoSimoes M. Head and neck lesions in a cohort irradiated in childhood for tinea capitis treatment. Lancet Infectious Diseases 201111 163-164. (doi:10.1016/S1473-3099(11)70047-0)

27 Brandão N. A roentgenterapia das tinhas do couro cabeludo (Aspectos técnicos e problemas). O Médico $19531857-864$.

28 Marques AR, Espadinha C, Frias MJ, Roque L, Catarino AL Sobrinho LG \& Leite V. Underexpression of peroxisome proliferatoractivated receptor (PPAR)gamma in PAX8/PPARgamma-negative thyroid tumours. British Journal of Cancer 200491 732-738. (doi:10.1038/sj.bjc.6601989)

29 Unger K, Zitzelsberger H, Salvatore G, Santoro M, Bogdanova T, Braselmann H, Kastner P, Zurnadzhy L, Tronko N, Hutzler P et al. Heterogeneity in the distribution of RET/PTC rearrangements within individual post-Chernobyl papillary thyroid carcinomas. Journal of Clinical Endocrinology and Metabolism 200489 4272-4279. (doi:10.1210/jc.2003-031870)

30 de Vries MM, Celestino R, Castro P, Eloy C, Maximo V, van der Wal JE, Plukker JTM, Links TP, Hofstra RMW, Sobrinho-Simoes M et al. RET/PTC rearrangement is prevalent in follicular Hurthle cell carcinomas. Histopathology 201261 833-843. (doi:10.1111/j. 1365-2559.2012.04276.x)

31 Trovisco V, Soares P, Soares R, Magalhaes J, Sa-Couto P \& Sobrinho-Simoes M. A new BRAF gene mutation detected in a case of a solid variant of papillary thyroid carcinoma. Human Pathology 200536 694-697. (doi:10.1016/j.humpath.2005.04. 011)

32 Romei C \& Elisei R. RET/PTC translocations and clinicopathological features in human papillary thyroid carcinoma. Frontiers in Endocrinology 20123 54. (doi:10.3389/fendo.2012. 00054 )

33 Fugazzola L, Puxeddu E, Avenia N, Romei C, Cirello V, Cavaliere A, Faviana P, Mannavola D, Moretti S, Rossi S et al. Correlation between B-RAFV600E mutation and clinico-pathologic parameters in papillary thyroid carcinoma: data from a multicentric Italian study and review of the literature. Endocrine-Related Cancer 200613 455-464. (doi:10.1677/erc.1.01086)

34 Lin JD, Hsueh C \& Huang BY. Papillary thyroid carcinoma with different histological patterns. Chang Gung Medical Journal 2011 34 23-34

35 Fridman MV, Savva NN, Krasko OV, Zborovskaya AA Mankovskaya SV, Kurt Werner S \& Demidchik YE. Clinical and pathologic features of "sporadic" papillary thyroid carcinoma registered in the years 2005 to 2008 in children and adolescents of Belarus. Thyroid 201222 1016-1024. (doi:10.1089/thy.2011. 0005)

36 Ito Y, Hirokawa M, Uruno T, Kihara M, Higashiyama T, Takamura Y, Miya A, Kobayashi K, Matsuzuka F \& Miyauchi A. Prevalence and biological behaviour of variants of papillary thyroid carcinoma: experience at a single institute. Pathology 2008 40 617-622. (doi:10.1080/00313020802320630)

37 Ertek S, Yilmaz NC, Cicero AF, Vurupalmaz O, Demiroz AS \& Erdogan G. Increasing diagnosis of thyroid papillary carcinoma 
follicular variant in south-east Anatolian region: comparison of characteristics of classical papillary and follicular variant thyroid cancers. Endocrine Pathology 201223 157-160. (doi:10.1007/ s12022-012-9216-9)

38 Yu XM, Schneider DF, Leverson G, Chen H \& Sippel RS. Follicular variant of papillary thyroid carcinoma is a unique clinical entity: a population-based study of 10,740 cases. Thyroid 2013. In press. (doi:10.1089/thy.2012.0453)

39 Sobrinho-Simoes M, Maximo V, Rocha AS, Trovisco V, Castro P, Preto A, Lima J \& Soares P. Intragenic mutations in thyroid cancer. Endocrinology and Metabolism Clinics of North America 200837 333-362, viii. (doi:10.1016/j.ecl.2008.02.004)

40 Lloyd RV, Buehler D \& Khanafshar E. Papillary thyroid carcinoma variants. Head and Neck Pathology 20115 51-56. (doi:10.1007/ s12105-010-0236-9)

41 Williams ED, Abrosimov A, Bogdanova T, Demidchik EP, Ito M, LiVolsi V, Lushnikov E, Rosai J, Sidorov Y, Tronko MD et al. Thyroid carcinoma after Chernobyl latent period, morphology and aggressiveness. British Journal of Cancer 200490 2219-2224. (doi:10138/sj.bjc.6601860)
42 Klemke M, Drieschner N, Belge G, Burchardt K, Junker K \& Bullerdiek J. Detection of PAX8-PPARG fusion transcripts in archival thyroid carcinoma samples by conventional RT-PCR. Genes, Chromosomes \& Cancer 201251 402-408. (doi:10.1002/ gcc.21925)

43 Dwight T, Thoppe SR, Foukakis T, Lui WO, Wallin G, Hoog A, Frisk T, Larsson C \& Zedenius J. Involvement of the PAX8/peroxisome proliferator-activated receptor gamma rearrangement in follicular thyroid tumors. Journal of Clinical Endocrinology and Metabolism $2003 \mathbf{8 8}$ 4440-4445. (doi:10.1210/jc.2002021690)

44 Berges O, Belkacemi Y \& Giraud P. Normal tissue tolerance to external beam radiation therapy: thyroid. Cancer Radiothérapie 201014 307-311. (doi:10.1016/j.canrad.2010.03.005)

Received 1 July 2013

Revised version received 19 August 2013

Accepted 21 August 2013 